\title{
Video raster stereography back shape reconstruction: a reliability study for sagittal, frontal, and transversal plane parameters
}

\author{
J. Schroeder $\cdot$ R. Reer $\cdot$ K. M. Braumann
}

Received: 16 May 2014/Revised: 3 November 2014/ Accepted: 3 November 2014/Published online: 26 November 2014

(C) The Author(s) 2014. This article is published with open access at Springerlink.com

\begin{abstract}
Purpose As reliability of raster stereography was proved only for sagittal plane parameters with repeated measures on the same day, the present study was aiming at investigating variability and reliability of back shape reconstruction for all dimensions (sagittal, frontal, transversal) and for different intervals.

Methods For a sample of 20 healthy volunteers, intraindividual variability (SEM and $\mathrm{CV} \%$ ) and reliability (ICC $\pm 95 \% \mathrm{CI}$ ) were proved for sagittal (thoracic kyphosis, lumbar lordosis, pelvis tilt angle, and trunk inclination), frontal (pelvis torsion, pelvis and trunk imbalance, vertebral side deviation, and scoliosis angle), transversal (vertebral rotation), and functional (hyperextension) spine shape reconstruction parameters for different test-retest intervals (on the same day, between-day, between-week) by means of video raster stereography.

Results Reliability was high for the sagittal plane (pelvis tilt, kyphosis and lordosis angle, and trunk inclination: ICC $>0.90$ ), and good to high for lumbar mobility $(0.86<$ ICC $<0.97)$. Apart from sagittal plane spinal alignment, there was a lack of certainty for a high reproducibility indicated by wider ICC confidence intervals. So, reliability was fair to high for vertebral side deviation
\end{abstract}

J. Schroeder · R. Reer · K. M. Braumann

Department of Sports Medicine, Faculty for Psychology and

Human Movement Science, Institute for Human Movement

Science, University of Hamburg, Turmweg 2, Hamburg 20148,

Germany

J. Schroeder $(\square)$

Schoenningstedter Str. 41 B, 21465 Reinbek, Germany

e-mail: schroeder.sport@gmx.de;

jan.schroeder@uni-hamburg.de and the scoliosis angle $(0.71<$ ICC $<0.95)$, and poor to good for vertebral rotation values as well as for frontal plane upper body and pelvis position parameters $(0.65<$ ICC $<0.92)$. Coefficients for the between-day and between-week interval were a little lower than for repeated measures on the same day. Variability (SEM) was less than $1.5^{\circ}$ or $1.5 \mathrm{~mm}$, except for trunk inclination. Relative variability $(\mathrm{CV})$ was greater in global trunk position and pelvis parameters (35-98\%) than in scoliosis (14-20\%) or sagittal sway parameters (4-8\%).

Conclusions Although we found a lower reproducibility for the frontal plane, raster stereography is considered to be a reliable method for the non-invasive, three-dimensional assessment of spinal alignment in normal non-scoliotic individuals in the sagittal plane and partly for scoliosis parameters, which fulfils scientific as well as practical recommendations for spine shape screening and monitoring, but cross-sectional or follow-up effect analyses should take into account the degree of reliability differing in various spine shape parameters. Further investigations should be conducted to analyse reliability in scoliosis patients with differing spinal deformities.

Keywords Spine shape $\cdot$ Three-dimensional reconstruction · Video raster stereography $\cdot$ Reliability

\section{Introduction}

The assessment of spinal curvatures is helpful for the understanding of low back pain syndromes [1]. A reliable imaging procedure of spinal alignment may offer classification models of spinal form variations leading to different therapy options $[2,3]$, or might be used for therapy monitoring, as well [4-6]. 
X-ray imaging is still serving as the 'gold standard' for the assessment of spinal form, spinal deformities or structural vertebral disorders [7], but non-radiating devices have been established in past decades for the non-invasive assessment of posture and spinal alignment, e.g. lateral photometric imaging $[3,8]$, or electro-mechanical inclinometers for back surface reconstruction, e.g. Spinal Mouse [9], or three-dimensional raster stereography back shape reconstruction devices with a minimised examiner's influence due to the optical, non-contact character of measurement needing no markers or detectors on the skin surface [10].

For the clinical environment or research applications, validity and reliability of those biomechanical assessment systems have not been sufficiently proved yet. For the examination of spinal mobility and back surface reconstruction by means of inclinometers, there exist satisfying reliability studies [11-14]. But for raster stereography, there is still a lack of reliability studies that are covering all parameters offered for a three-dimensional spinal form analysis.

So far, intra- and inter-examiner reliability studies of raster stereographic sagittal plane spine shape parameters have been evaluated and published internationally $[15,16]$. But those studies were limited: frontal and coronal plane parameters were not included and data acquisition for test and retest took place on the same day. One study-published in German-included frontal plane parameters, or axial vertebral deviations, but was limited due to the sample characteristics [17].

As the role of examiner influences appeared not to be crucial-no markers or detectors on skin surface set or conducted by an examiner-and with respect to the knowledge of the relation between intra- and inter-examiner reliability [16], the present investigation was focussing on the intra-examiner reliability and the intra-individual variability as well as the group mean stability of raster stereography parameters in all three dimensions (sagittal, frontal, coronal plane)_ as recommended earlier [16]—in four repeated measures within 1 week.

\section{Methods}

\section{Subjects}

A total of 20 persons (age $25.4 \pm 5.5$ years; BMI $\left.22.8 \pm 2.7 \mathrm{~kg} / \mathrm{m}^{2}\right)$, females $(n=9)$ and males $(n=11)$, were recruited as volunteers having been explicitly informed about the investigation and the non-radiating character of physical examinations (Table 1). Data were anonymised after the examination and analysed for the purpose of a reliability analysis based on four repeated measures: between-instants within 5 min on the same day, between-day at the same time the following day, and between-week at the same time the following week.

The participants-all of them associated with our institution-were included, if there was no diagnosis dealing with back pain complaints, no serious back pain history for 2 years, and no back pain at all in the last 6 months. Indeed, there was no actual back pain (CR10 pain scale: $0.8 \pm 1.1$ pts.) [18] nor were there any functional deficits due to a back pain history (Oswestry Disability Index: $4.0 \pm 3.3 \%$ ) [19] in the whole sample. Therefore, accompanying confounding effects on spinal shape could be excluded.

\section{Equipment}

Spine shape parameters were calculated by means of video raster stereography (Formetric ${ }^{\circledR}$-System, Diers International, Schlangenbad, Germany), a non-invasive device for an indirect and high resolution back shape reconstruction (reconstruction error $0.2-0.5 \mathrm{~mm}$; resolution $10 \mathrm{pts} . / \mathrm{cm}^{2}$ ) [10] (Table 2).

Specific back surface landmarks-like the vertebra prominens (VP), the beginning of the rima ani representing the sacrum point (SP), and the right and left lumbar dimple (DR, resp. DL) representing the position of spinae iliaca posterior superior (SIPS) of the pelvis bones-were recognised automatically to build up a Cartesian coordinate system (Fig. 1). This coordinate system served as calibration reference frame for a three-dimensional surface reconstruction using triangulation equations that ensured a valid correlation between back shape reconstruction and radiographic assessments of the anatomy of spine and pelvis [20, 21]. For a better understanding of geometry and corresponding anatomical landmarks, spine shape parameters serving as dependent variables were illustrated (Fig. 2). ${ }^{1}$

\section{Test protocol}

For the static assessment of spinal alignment, the participants were given only few instructions: They had to stand on a platform with their backs to the camera, their heels placed at the end of the platform, staying immobile while looking straight ahead (Fig. 1). Back shape was recorded over a time period of $5 \mathrm{~s}$ (10 frames/s), and spine shape parameters were calculated as an average of these 50 frames, nearly in real time.

\footnotetext{
1 The parameter named scoliosis angle should not be confused with the radiographic Cobb angle, although it referred to the same idea. Scoliosis angle was calculated based on reconstructed vertebral bodies, ignoring individual bony deformities, and not on $\mathrm{x}$-ray visible concrete structures.
} 
Table 1 Anthropometrics for the whole sample and separated for males and females (mean \pm standard deviation)

\begin{tabular}{lllllll}
\hline & Age (years) & Height $(\mathrm{m})$ & Weight $(\mathrm{kg})$ & BMI $\left(\mathrm{kg} / \mathrm{m}^{2}\right)$ & CR10 $(\mathrm{pts})$ & ODI $(\%)$ \\
\hline Total $(n=20)$ & $25.4 \pm 5.5$ & $1.74 \pm 9.0$ & $69.6 \pm 12.8$ & $22.8 \pm 2.7$ & $0.8 \pm 1.1$ & $4.0 \pm 3.3$ \\
Females $(n=9)$ & $23.2 \pm 3.2$ & $1.67 \pm 6.0$ & $59.7 \pm 7.3$ & $21.4 \pm 2.0$ & $1.0 \pm 1.2$ & $4.0 \pm 3.3$ \\
Males $(n=11)$ & $27.2 \pm 6.5$ & $1.80 \pm 6.0$ & $77.7 \pm 10.4$ & $23.9 \pm 2.6$ & $0.6 \pm 1.0$ & $4.0 \pm 3.5$ \\
\hline
\end{tabular}

Values are in mean $\pm \mathrm{SD}$

$B M I$ Body Mass Index, CR10 pain scale values (Categorial Relational Score from 0 to 10 points), ODI functional disability score (Oswestry Disability Index from 0 to $100 \%$ ), $S D$ standard deviation, $n$ sample size

Table 2 Spine shape parameters, shortcuts, and a description of anatomy and corresponding geometry

\begin{tabular}{|c|c|c|}
\hline Spine shape parameter & Shortcut & Explication \\
\hline Trunk inclination (mm) & Tr-Inc & Plumb line deviation from VP to DM in the sagittal plane (Fig. 2) \\
\hline Trunk imbalance (mm) & $\operatorname{Tr}-\operatorname{Imb}$ & Plumb line deviation from VP to DM in the frontal plane (Fig. 1) \\
\hline Pelvis imbalance (mm) & P-Imb & $\begin{array}{l}\text { Deviation of the axis of lumbar dimples to the floor line in the } \\
\text { frontal plane (Fig. 1) }\end{array}$ \\
\hline Pelvis torsion $\left(^{\circ}\right)$ & P-Tors & Torsion between left and right side pelvis bones (os ilium) \\
\hline Pelvis tilt $\left(^{\circ}\right)$ & P-Tilt & $\begin{array}{l}\text { Angle between plumb line and a tangent on the lumbar dimples in } \\
\text { the sagittal plane (Fig. 2) }\end{array}$ \\
\hline Kyphosis angle (ICT-ITL) $\left(^{\circ}\right)$ & KA & $\begin{array}{l}\text { Maximum thoracic angle calculated from ICT and ITL triangles } \\
\text { (Fig. 2) }\end{array}$ \\
\hline Lordosis angle (ITL-ILS) $\left(^{\circ}\right)$ & LA & $\begin{array}{l}\text { Maximum lumbar angle calculated from ITL and ILS triangles } \\
\text { (Fig. 2) }\end{array}$ \\
\hline Surface rotation (root mean square) $\left(^{\circ}\right)$ & ROT-rms & $\begin{array}{l}\text { Vertebral rotation measured perpendicular to back surface over the } \\
\text { processus spinosus as the central tendency from VP to DM } \\
\text { (Fig. 2) }\end{array}$ \\
\hline Surface rotation (maximum amplitude) $\left(^{\circ}\right)$ & ROT-amp & $\begin{array}{l}\text { Vertebral rotation measured perpendicular to back surface over the } \\
\text { processus spinosus as the maximal variation from VP to DM } \\
\text { (Fig. 2) }\end{array}$ \\
\hline Side deviation from symmetry line (root mean square) $(\mathrm{mm})$ & SIDE-rms & $\begin{array}{l}\text { Lateral deviations of vertebral bodies from symmetry line in the } \\
\text { frontal plane as the central tendency from VP to DM (Fig. 2) }\end{array}$ \\
\hline Side deviation (maximum amplitude) (mm) & SIDE-amp & $\begin{array}{l}\text { Lateral deviations of vertebral bodies from symmetry line in the } \\
\text { frontal plane as the maximal variation from VP to DM (Fig. 2) }\end{array}$ \\
\hline Scoliosis angle $\left(^{\circ}\right)$ & Scoliosis & $\begin{array}{l}\text { Maximum angle between tangents under calculated vertebral } \\
\text { bodies opening in the frontal plane (Fig. 1) }\end{array}$ \\
\hline Lumbar flexibility angle $\left(^{\circ}\right)$ & Lumb-flex & $\begin{array}{l}\text { Lumbar mobility from neutral to maximally extended position as } \\
\text { the difference of the corresponding LA (Fig. 3) }\end{array}$ \\
\hline
\end{tabular}

$V P$ vertebra prominens, $D M$ midpoint between dimples, $I C T$ inflectional point of the curvature from cervical to thoracic spine, ITL inflectional point of the curvature from thoracic to lumbar spine, $I L S$ inflectional point of the curvature from lumbar to sacral spine

For the dynamic examination of lumbar mobility, the participants started like they did for the static assessment. Then they clasped their head above the neck to present their vertebrae prominens to the camera and began a backward bending movement up to the maximum extension. Evasion manoeuvres in the hip or knee joint could be self controlled with the help of a contact bar at the back of their thighs. This bar was serving as a tactile feed back instrument to take care of the movement quality control, because knee bending and hip evasion movements would have led to an upper body backward inclination, but not to the intended maximum segmental hyperextension of the lumbar spine.
Backward bending was recorded over a time period of $10 \mathrm{~s}$ (10 frames/per s). The mobility was calculated as the difference between the unforced starting and the maximum hyperextension position at the end of the $10 \mathrm{~s}$ (Fig. 3). The examiner was well experienced and used standard instructions. $^{2}$ If the examiner decided that the execution of the movements had not been totally correct, the test was repeated.

\footnotetext{
${ }^{2}$ Phase 1: 'do not' move', 'look straight ahead', Phase 2: 'grab your head', 'close your elbows', 'start bending backward', Phase 3: 'do not leave the contact bar', 'bend further on'.
} 

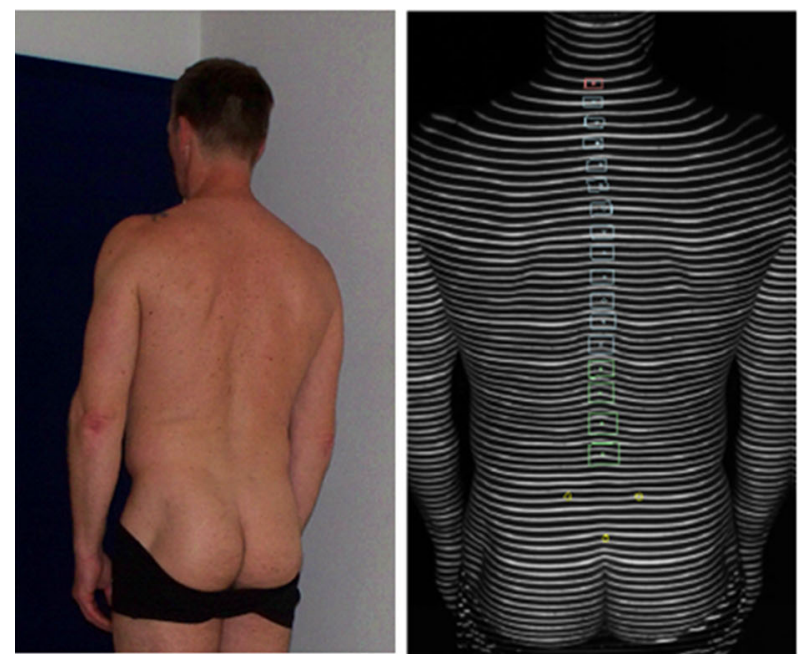

Fig. 1 Data assessment in free bipedal standing, raster projection lines with animated landmarks (yellow dots) and vertebral bodies (C7 red, T1-T12 blue, L1-L4 green) on back surface, back surface reconstruction with red areas (convex curvature), blue areas (concave curvature), and yellow dots (axis for coordinate system: VP-SP

\section{Statistics}

Data were described as mean \pm standard deviation (SD). Normal distribution was verified (Kolmogorof-Smirnof test). Group mean differences were proved (one-way ANOVA for repeated measures). Significance was accepted at a level of $P \leq 0.05$. Intra-individual variability was expressed as standard error of the measurement (SEM) and as coefficient of variation (CV \%) based on four repeated measures, being displayed as group means for the whole sample. The Intra-Class-Correlation coefficient with corresponding confidence intervals (ICC $\pm 95 \% \mathrm{CI}$ ) was calculated pairwise and for the total of all measures. Coefficients of more than 0.90 indicated a high, $0.80-0.89$ a good, $0.70-0.70$ a fair, and less than 0.69 a poor reliability.

\section{Results}

\section{Stability}

There were no significant changes within group means from the first to the last time of spinal form assessment in any parameter $\left(P>0.050, \eta^{2}\right.$ ranging between 0.001 and 0.180) (Table 3).

\section{Variability}

Intra-individual variability of four repeated measures within 1 week revealed little absolute variations (SEM)

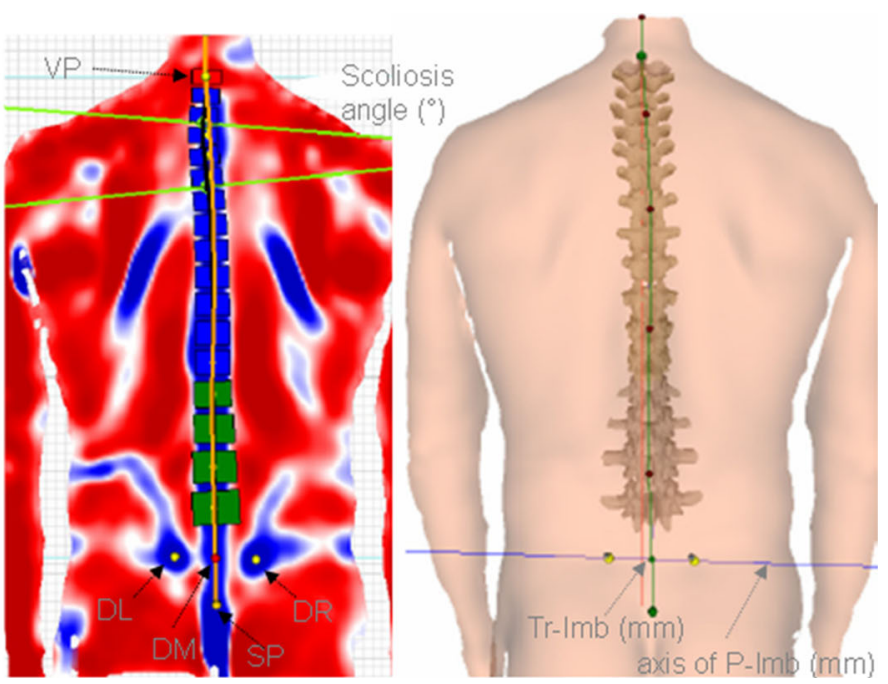

and DL-DR), and frontal plane spine shape parameters: Trunk imbalance, Pelvis imbalance, and Scoliosis angle (Table 2). VP vertebra prominens, $S P$ sacrum point, $D M$ midpoint between dimples, $D L$ left and $D R$ right dimple

and more discriminating relative values $(\mathrm{CV})$, ranging from $4.4 \%$ (thoracic kyphosis) to $98.2 \%$ (trunk inclination) (Table 3).

- Parameters describing the sagittal curvature (thoracic, lumbar, sacral sway) were the least varying (CV 4.4-7.9\%, SEM $0.6^{\circ}-0.9^{\circ}$ ).

- Parameters describing scoliosis determinants-vertebral rotation (coronal plane) or side deviation (frontal plane) varied between 14.1 and $20.5 \%$ (SEM $0.3^{\circ}-$ $0.9^{\circ}$, and $0.4-0.7 \mathrm{~mm}$, respectively).

- Parameters describing the frontal and sagittal plane upper body global position as well as frontal plane pelvis position were varying most widely $(\mathrm{CV}$ 35.8-98.2 \%, SEM 0.7-3.0 mm).

- Lumbar mobility test results were varying wider $(\mathrm{CV}=$ $12.9 \%, \mathrm{SEM}=1.5^{\circ}$ ) than lumbar angles assessed under static conditions $\left(\mathrm{CV}=4.9 \%, \mathrm{SEM}=0.8^{\circ}\right)$.

\section{Reliability}

Short-term reliability assessed on the same day was higher than the between-day reliability, except for the pelvis torsion. Overall correlation coefficients were affected by the short-term coefficients, and therefore showed higher reliability values than the between-day analyses (Table 4).

Between-day and between-week reliability was comparable, except for the pelvis torsion (between-day was higher), for frontal plane scoliosis parameters (scoliosis angle, vertebral side deviation amplitude), and for the lumbar mobility (between-week was higher). 

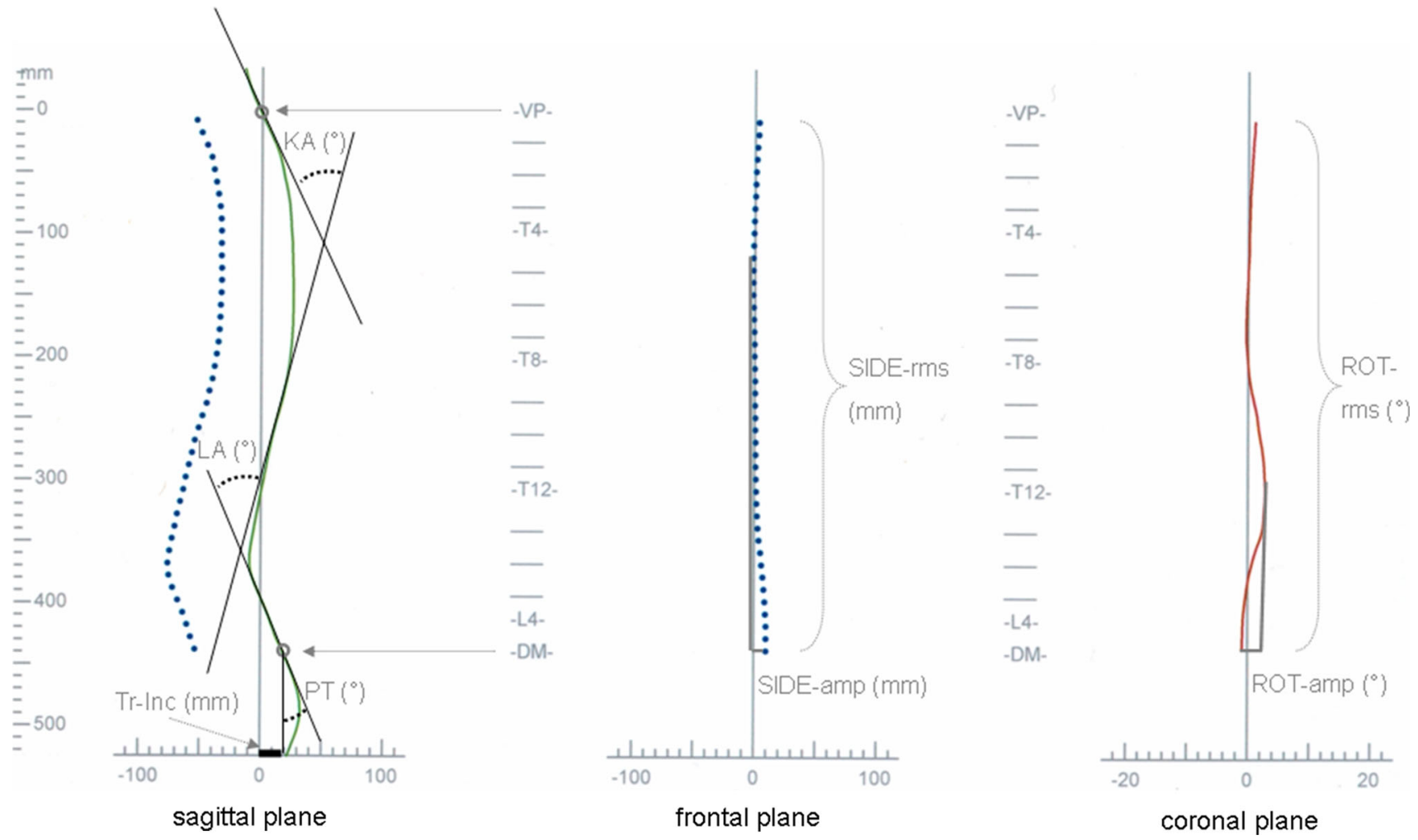

Fig. 2 Illustration of spinal alignment curves and back shape reconstruction parameters (Table 2)
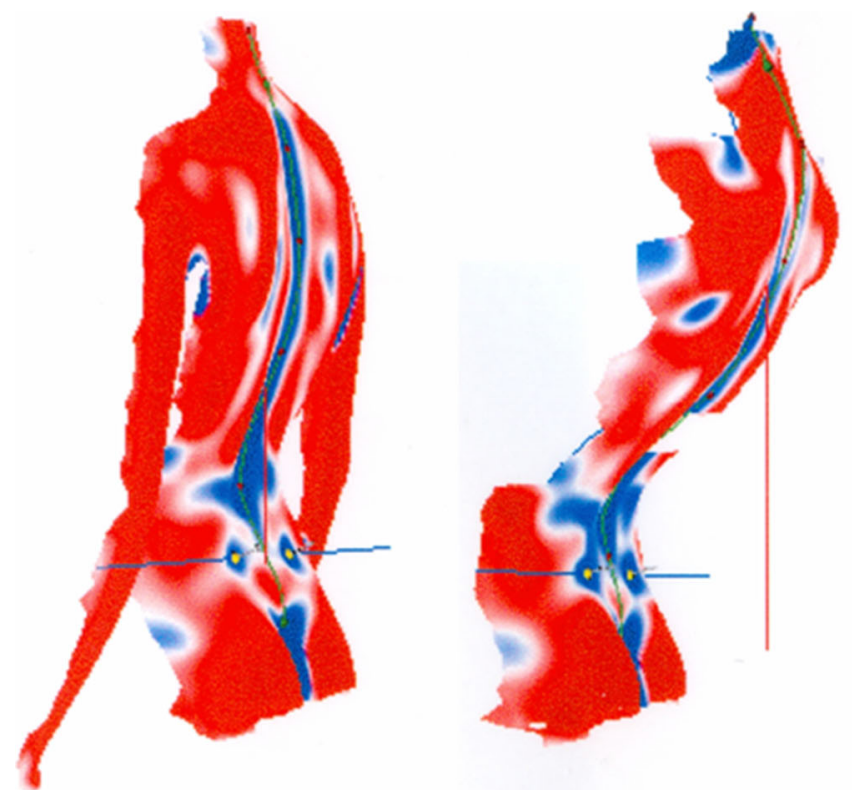
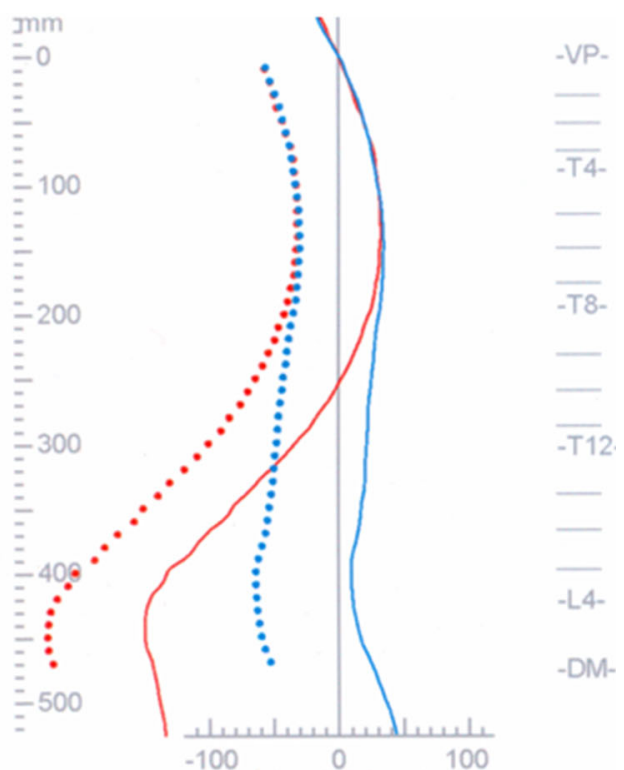

Fig. 3 Spinal mobility-backward bending in the sagittal plane with surface reconstructions at the upright standing starting point and at the end of the task (left) and lumbar flexibility angle $\left(^{\circ}\right)$ illustrated as the

difference of the lumbar lordosis angles between upright standing and maximally hyper-extended position (right)

high (ICC 0.938-0.994), irrespective of the analysed interval.

- Reliability of scoliosis associated parameters (vertebral rotation and side deviation, and scoliosis angle) was 
Table 3 Descriptives (mean $\pm \mathrm{SD}$ ), intra-individual variability expressed as relative (CV \%) and absolute (SEM) values, and group mean differences (one-way ANOVA) in four repeated measures

\begin{tabular}{|c|c|c|c|c|c|c|c|c|c|}
\hline & $\mathrm{T} 1( \pm \mathrm{SD})$ & $\mathrm{T} 2( \pm \mathrm{SD})$ & $\mathrm{T} 3( \pm \mathrm{SD})$ & $\mathrm{T} 4( \pm \mathrm{SD})$ & $\mathrm{CV}(\%)$ & SEM & $F$ & $P$ & $\eta^{2}$ part. \\
\hline Tr-Inc (mm) & $17.8 \pm 20.5$ & $13.9 \pm 19.7$ & $12.7 \pm 20.3$ & $16.2 \pm 22.2$ & 98.2 & 3.0 & 0.577 & 0.457 & 0.029 \\
\hline $\operatorname{Tr}-\operatorname{Imb}(\mathrm{mm})$ & $8.4 \pm 5.0$ & $8.8 \pm 5.8$ & $9.1 \pm 4.7$ & $8.9 \pm 5.0$ & 35.8 & 1.3 & 0.247 & 0.625 & 0.013 \\
\hline P-Imb (mm) & $4.0 \pm 2.9$ & $4.8 \pm 3.6$ & $3.8 \pm 3.5$ & $3.7 \pm 4.2$ & 45.0 & 0.7 & 0.762 & 0.394 & 0.039 \\
\hline P-Tors $\left(^{\circ}\right)$ & $2.1 \pm 1.4$ & $2.0 \pm 1.9$ & $2.4 \pm 1.6$ & $2.6 \pm 1.7$ & 48.0 & 0.4 & 4.161 & 0.056 & 0.180 \\
\hline P-Tilt $\left(^{\circ}\right)$ & $18.7 \pm 7.1$ & $19.0 \pm 7.1$ & $18.7 \pm 6.6$ & $18.9 \pm 7.0$ & 7.9 & 0.6 & 0.012 & 0.914 & 0.001 \\
\hline $\mathrm{KA}\left({ }^{\circ}\right)$ & $45.3 \pm 9.4$ & $46.4 \pm 9.8$ & $45.1 \pm 9.0$ & $45.6 \pm 10.1$ & 4.4 & 0.9 & 0.050 & 0.825 & 0.003 \\
\hline LA $\left(^{\circ}\right)$ & $39.1 \pm 11.0$ & $39.4 \pm 10.9$ & $39.0 \pm 10.9$ & $39.2 \pm 10.5$ & 4.9 & 0.8 & 0.010 & 0.922 & 0.001 \\
\hline ROT-rms $\left({ }^{\circ}\right)$ & $3.8 \pm 1.4$ & $3.5 \pm 1.1$ & $3.6 \pm 1.4$ & $3.6 \pm 1.1$ & 18.3 & 0.3 & 0.576 & 0.457 & 0.029 \\
\hline ROT-amp $\left(^{\circ}\right)$ & $8.6 \pm 3.3$ & $8.3 \pm 2.6$ & $8.7 \pm 2.2$ & $7.9 \pm 2.3$ & 14.2 & 0.6 & 0.683 & 0.419 & 0.035 \\
\hline SIDE-rms (mm) & $3.8 \pm 1.9$ & $4.2 \pm 2.0$ & $4.0 \pm 2.3$ & $4.3 \pm 2.0$ & 20.5 & 0.4 & 1.921 & 0.182 & 0.092 \\
\hline SIDE-amp (mm) & $9.5 \pm 2.8$ & $9.7 \pm 3.2$ & $10.0 \pm 2.8$ & $10.4 \pm 3.4$ & 14.3 & 0.7 & 2.955 & 0.102 & 0.135 \\
\hline Scoliosis $\left({ }^{\circ}\right)$ & $12.1 \pm 4.3$ & $12.5 \pm 4.5$ & $12.1 \pm 4.0$ & $12.0 \pm 3.8$ & 14.1 & 0.8 & 0.065 & 0.802 & 0.003 \\
\hline Lumb-flex $\left(^{\circ}\right)$ & $24.7 \pm 10.3$ & $26.1 \pm 9.9$ & $24.3 \pm 8.8$ & $24.9 \pm 9.3$ & 12.9 & 1.5 & 0.090 & 0.768 & 0.005 \\
\hline
\end{tabular}

Table 4 Reliability coefficients (ICC \pm CI $95 \%$ ) for pairwise correlations and the total of four tests

\begin{tabular}{|c|c|c|c|c|}
\hline & $\begin{array}{l}\text { ICC between-instant } \\
( \pm \text { CI } 95 \%)\end{array}$ & $\begin{array}{l}\text { ICC between-day } \\
( \pm \text { CI } 95 \%)\end{array}$ & $\begin{array}{l}\text { ICC between-week } \\
( \pm \text { CI } 95 \%)\end{array}$ & ICC total $( \pm \mathrm{CI} 95 \%)$ \\
\hline Tr-Inc (mm) & $0.994 * * *(0.858-0.978)$ & $0.938 * * *(0.843-0.975)$ & $0.943^{* * *}(0.855-0.977)$ & $0.964 * * *(0.929-0.984)$ \\
\hline $\operatorname{Tr}-\operatorname{Imb}(\mathrm{mm})$ & $0.786^{* *}(0.459-0.915)$ & $0.687 * *(0.210-0.876)$ & $0.678 * *(0.187-0.873)$ & $0.838 * * *(0.680-0.929)$ \\
\hline P-Imb (mm) & $0.825^{* * *}(0.558-0.931)$ & $0.743 *(0.351-0.898)$ & $0.744 *(0.354-0.899)$ & $0.919 * * *(0.840-0.964)$ \\
\hline P-Tors $\left(^{\circ}\right)$ & $0.775^{* * *}(0.433-0.911)$ & $0.909 * * *(0.771-0.964)$ & $0.721 * *(0.294-0.889)$ & $0.890 * * *(0.783-0.952)$ \\
\hline P-Tilt $\left({ }^{\circ}\right)$ & $0.980 * * *(0.949-0.992)$ & $0.969 * * *(0.922-0.988)$ & $0.965 * * *(0.911-0.986)$ & $0.986 * * *(0.973-0.994)$ \\
\hline $\mathrm{KA}\left({ }^{\circ}\right)$ & $0.975 * * *(0.938-0.990)$ & $0.977 * * *(0.941-0.991)$ & $0.965 * * *(0.910-0.986)$ & $0.982 * * *(0.964-0.992)$ \\
\hline LA $\left({ }^{\circ}\right)$ & $0.990 * * *(0.974-0.996)$ & $0.972 * * *(0.929-0.989)$ & $0.976 * * *(0.941-0.991)$ & $0.987 * * *(0.974-0.994)$ \\
\hline ROT-rms $\left(^{\circ}\right)$ & $0.857 * * *(0.639-0.943)$ & $0.658 *(0.136-0.865)$ & $0.687 * * *(0.208-0.876)$ & $0.845^{* * *}(0.693-0.932)$ \\
\hline ROT-amp $\left(^{\circ}\right)$ & $0.908 * * *(0.768-0.964)$ & $0.785^{* * *}(0.458-0.915)$ & $0.762 * *(0.398-0.906)$ & $0.903 * * *(0.808-0.957)$ \\
\hline SIDE-rms (mm) & $0.933 * * *(0.831-0.973)$ & $0.813 * * *(0.529-0.926)$ & $0.877 * * *(0.689-0.951)$ & $0.935 * * *(0.872-0.972)$ \\
\hline SIDE-amp (mm) & $0.853 * * *(0.630-0.942)$ & $0.718 * *(0.286-0.888)$ & $0.871 * * *(0.673-0.949)$ & $0.897 * * *(0.797-0.955)$ \\
\hline Scoliosis $\left({ }^{\circ}\right)$ & $0.946^{* * *}(0.864-0.979)$ & $0.788 * * *(0.464-0.916)$ & $0.856^{* * *}(0.637-0.943)$ & $0.915^{* * *}(0.831-0.963)$ \\
\hline Lumb-flex $\left({ }^{\circ}\right)$ & $0.969 * * *(0.922-0.988)$ & $0.862 * * *(0.651-0.945)$ & $0.933 * * *(0.832-0.974)$ & $0.957 * * *(0.914-0.981)$ \\
\hline
\end{tabular}

Levels of significance $* p \leq 0.05 * * p \leq 0.01 * * * p \leq 0.001$

good or high (ICC 0.857-0.946) for the short-term interval, but lower for the between-day and betweenweek intervals (ICC 0.658-0.877).

- Trunk imbalance assessment revealed poor or fair reliability coefficients (ICC 0.678-0.786).

- Reliability of pelvis imbalance was fair; it was good only for the short-term interval (ICC 0.743-0.825).

- Pelvis torsion assessment was highly reliable betweendays (ICC $=0.909$ ), but almost fair for other intervals (ICC 0.721-0.775), while the overall coefficient appeared to be good (ICC $=0.890)$.

- Reliability of lumbar mobility testing was good or even high (ICC 0.862-0.969), but lower than for the assessment of lordosis angles under static conditions (ICC 0.972-0.990).

\section{Discussion}

Stability

According to earlier studies, we analysed group mean stability and did not find significant changes in any spine shape parameter, indicating assumed parameter stability within 1 week including four repeated measures as could be established previously for global sagittal spinal form 
parameters assessed using a surface inclinometer [14]. Therefore, longitudinal monitoring should be considered not to be affected by systematic processes like learning or familiarisation.

\section{Variability}

By comparing variations within repeated measures of the thoracic kyphosis angle in a 'back phantom' and a human being Goh et al. [15] could distinguish the major role of behavioural stance positioning effects rather than technical reasons as a confounder for reproducibility ('phantom' 0.4-1.3\% vs. 'volunteer' 2.4-3.0\%). Actually, intraindividual variability expressed as absolute values (SEM) revealed only little parameter variations ranging from less than one degree or millimetre, respectively, to maximally $1.5^{\circ}$ (lumbar mobility) or $3 \mathrm{~mm}$ (trunk inclination) (Table 3). Earlier reliability studies dealing with raster stereography did not focus on intra-individually spreading spine shape parameters in repeated measures [16], or decided to calculate the relative variation ( $\mathrm{CV} \%$ ), only [15]. Mannion and collaborators [14] analysed betweenday intra-individual variations as standard error (SEM) for a skin surface detecting inclinometer (Spinal Mouse ${ }^{\circledR}$ ). They found considerably higher standard errors for their global thoracic and lumbar angles (SEM: $4.2^{\circ}$, and $2.5^{\circ}$, respectively) than we $\operatorname{did}\left(\operatorname{SEM}<1^{\circ}\right)$. These variations were, inter alia, due to positioning. But contrary to the nontouch raster stereography, the practical application of the Spinal Mouse ${ }^{\circledR}$ inclinometer undoubtedly suffered of immanent inter-examiner influences, spine shape assessment results being determined not only by the individuals' back shape and by varying posture but also, not least, by the grade (i.e. lack) of the examiner's experience.

Expressed as relative variation (CV \%), pelvis and global upper body position varied more (36-98\%) than scoliosis determinants (14-21\%), while sagittal spine shape parameters varied least (4-8\%) in the present study. As there were no comparable studies covering all three dimensions of spinal alignment calculating coefficients of variability, our results could be discussed only for the kyphosis angle in this point, where Goh et al. [15] found a relative variation of about $3 \%$. Being aware that those findings were based on repeated measures on the same day, our results of $4.4 \%$ kyphosis angle variation assessed within 1 week were assumed to be comparably good.

\section{Reliability}

In the present study, sagittal spine shape parameters showed the highest reliability coefficients (ICC 0.938-0.990). Functional testing of lumbar mobility was also almost highly reliable (ICC 0.862-0.969), while reliability for scoliosis determinants, frontal plane imbalance of pelvis and upper body was ranging from poor to high coefficients (ICC 0.658-0.946). In general, short-term reliability was higher than for the between-day or between-week interval.

Our results were in line with earlier studies examining sagittal spinal alignment within repeated measures on the same day (ICC or Cronbachs $\alpha$ : 0.92-0.99) [15, 16]. Looking at the between-day reliability, comparisons were possible only with the Spinal Mouse ${ }^{\circledR}$, where global sagittal sway parameters showed coefficients slightly lower (ICC: 0.73-0.92) than observed in the present study [14]. Obviously, the above-mentioned examiner's influencemanually conducted skin surface detection-was a confounding variable affecting reproducibility remarkably more than the non-touch raster stereography in static posture as well as in dynamic mobility testing.

Reliability of scoliosis determinants has not yet been investigated as between-day or between-week reliability anywhere else. So far, the short-term reliability has merely been examined within a sample of scoliosis patients: vertebral rotation and side deviation could be established as being highly reliable ( $r>0.94$ and $r>0.96$, respectively) [17]. Those reliability coefficients were higher compared to the present study (ICC: 0.86-0.95) investigating volunteers without any back deformities, probably due to statistical reasons. Wider spreading parameter distributions among the scoliosis patients were easing higher correlation coefficients compared to more homogeneous non-scoliotic individuals in the present study, and in general ICC correlation coefficients tend to be lower than Pearson correlation coefficients, because the ICC took into account the absolute differences of the individual's values, which were ignored by the Pearson correlation coefficients in earlier studies [17].

Reliability of frontal plane parameters, trunk and pelvis imbalance, for the short-term analysis was almost fair (ICC $=0.79$ ) or even good (ICC $=0.83)$, respectively, but it should be kept in mind that between-day and betweenweek coefficients were remarkably lower for scoliosis determinants as well as for frontal plane parameters, marking a poor to good reliability (Table 4), which should be taken into account especially for spine shape monitoring investigations.

To the authors' knowledge, there have been no earlier internationally published investigations discussing frontal plane spine shape parameter reliability. Technical background reasons might possibly be helpful for the discussion of pelvis imbalance, pelvis torsion, and trunk imbalance, which all depend more than other spine shape parameters on the correct automatic recognition of the lumbar dimple anatomy.

Lumbar dimple position represented the SIPS as bony pelvis structures necessary to build up the Cartesian coordinate system serving as calibration frame for back shape reconstruction $[10,22]$. Confounding soft tissue influences 
should be considered especially for the lumbar dimple area. Inter-individually varying tissue properties affected by subcutaneous matter-affected more than in other back surface regions-might lead to differing errors within repeated measures, affecting reliability results and the error of measurements [21], although Body Mass Index could not be identified as a relevant confounder, so far $[15,16]$.

\section{Limitations}

With respect to the knowledge of earlier investigations, showing inter-examiner reliability coefficients very similar to or even higher than the intra-examiner reliability coefficients for sagittal plane parameters [16], and taking into account the automatic and non-touch character of raster stereography data assessment with an assumed only minor examiner influence, we did not test inter-examiner reliability. This was considered to be reasonable for the static data assessment of spinal alignment, but might be limiting for the dynamic assessment of lumbar mobility, where examiner instructions and decisions play a more influential, potentially confounding part.

\section{Conclusions}

Reproducibility of the non-invasive spine shape reconstruction in normal non-scoliotic individuals by means of video raster stereography is supposed to be helpful for clinical applications in screening and monitoring, although confidence intervals of reliability coefficients were indicating a lack of certainty for a high reliability in spine shape parameters apart from the sagittal plane. Effect analyses should take into account the degree of reliability differing in several spine shape parameters, whenever intervention effects are discussed. Furthermore, there is a need for additional research dealing with scoliosis patients of different degrees of spinal deformities.

\section{Conflict of interest None.}

Open Access This article is distributed under the terms of the Creative Commons Attribution License which permits any use, distribution, and reproduction in any medium, provided the original author(s) and the source are credited.

\section{References}

1. Roussouly P, Nnadi C (2010) Sagittal plane deformity: an overview of interpretation and management. Eur Spine J 19:1824-1836

2. Dolphens M, Cagnie B, Coorevits P, Vleeming A, Palmans T, Danneels L (2014) Posture class prediction of pre-peak height velocity subjects according to gross body segment orientations using linear discriminant analysis. Eur Spine J 23:530-535
3. Smith A, O'Sullivan P, Straker L (2008) Classification of sagittal thoraco-lumbo-pelvic alignment of the adolescent spine in standing and its relationship to low back pain. Spine 33:2101-2107

4. Rigo M, Quera-Salvá G, Villagrasa M, Ferrer M, Casas A (2007) Effect of specific exercises on the sagittal profile of scoliotic spines. Scoliosis 2(Suppl 1):S7

5. Weiß HR, Dieckmann J, Gerner HJ (2003) The practical use of surface topography: following up patients with Scheuermann's disease. Pediatr Rehabil 6:39-45

6. Weiß HR, Klein R (2006) Improving excellence in scoliosis rehabilitation. Pediatr Rehabil 9:190-200

7. Langensiepen S, Semler O, Sobottke R, Fricke O, Franklin J, Schönau E, Eysel P (2013) Measuring procedures to determine the Cobb angle in idiopathic scoliosis: a systematic review. Eur Spine J 22:2360-2371

8. Roussouly P, Pinheiro-Franco JL (2011) Sagittal parameters of spine: biomechanical approach. Eur Spine J 20(Suppl 5):578-585

9. Post RB, Leferink VJM (2004) Spinal mobility: sagittal range of motion measured with the SpinalMouse, a new non-invasive device. Arch Orthop Trauma Surg 124:187-192

10. Drerup B, Hierholzer E (1994) Back shape measurement using video rasterstereography and three-dimensional reconstruction of spinal shape. Clin Biomech 9:28-36

11. Gelalis ID, DeFrate LE, Stafilas KS, Pakos EE, Kang JD, Gilbertson LG (2009) Three-dimensional analysis of cervical spine motion: reliability of a computer assisted magnetic tracking device compared to inclinometer. Eur Spine J 18:276-281

12. Saur P, Ensink FB, Frese K, Seeger D, Hildebrandt J (1996) Lumbar range of motion: reliability and validity of the inclinometer technique in the clinical measurement of trunk flexibility. Spine 21:1332-1338

13. Williams R, Binkley J, Bloch R, Goldsmith CH, Minuk T (1993) Reliability of the modified-modified Schöber and double inclinometer methods for measuring lumbar flexion and extension. Phys Ther 73:33-44

14. Mannion AF, Knecht K, Balaban G, Dvorak J, Grob D (2004) A new skin-surface device for measuring the curvature and global and segmental ranges of motion of the spine: reliability of measurements and comparison with data reviewed from the literature. Eur Spine J 13:122-136

15. Goh S, Price RI, Leedman PJ, Singer KP (1999) Rasterstereographic analysis of the thoracic sagittal curvature: a reliability study. J Musculoskelet Res 3:137-142

16. Mohokum M, Mendoza S, Wolf U, Sitter H, Jürgen RP, Skwara A (2010) Reproducibility of rasterstereography for kyphotic and lordotic angles, trunk length, and trunk inclination. A reliability study. Spine 35:1353-1358

17. Weiß HR, El Obeidi N, Lohschmidt K, Verres C (1998) Die automatische Oberflächenvermessung des Rückens: Technische Fehler. Phys Rehab Kur Med 8:118-122

18. Borg G (1998) Borg's perceived exertion and pain scales. Human Kinetics, Champaign

19. Fairbanks JC, Pynsent PB (2000) The oswestry disability index. Spine 25:2940-2953

20. Drerup B, Hierholzer E (1987) Automatic localization of anatomical landmarks on the back surface and construction of a body-fixed coordinate system. J Biomech 20:961-970

21. Drerup B, Hierholzer E (1987) Movement of the human pelvis and displacement of related anatomical landmarks on the body surface. J Biomech 20:971-977

22. Drerup B, Ellger B, Meyer zu Bentrup F, Hierholzer E (2001) Functional examinations with rasterstereography. A new method for the biomechanical analysis of skeletal geometry. Orthopade $30: 242-250$ 